\title{
Article
}

\section{Characterisation of the dispersion in polymer flame retarded nanocomposites}

\author{
SAMYN, F, BOURBIGOT, S, JAMA, C, BELLAYER, S, NAZARE, S, Hull, \\ T Richard, FINA, A, CASTROVINCI, A and CAMINO, G
}

Available at http://clok.uclan.ac.uk/1085/

SAMYN, F, BOURBIGOT, S, JAMA, C, BELLAYER, S, NAZARE, S, Hull, T Richard ORCID: 0000-0002-7970-4208, FINA, A, CASTROVINCI, A and CAMINO, G (2008) Characterisation of the dispersion in polymer flame retarded nanocomposites. European Polymer Journal, 44 (6). pp. 1631-1641. ISSN 00143057

It is advisable to refer to the publisher's version if you intend to cite from the work. http://dx.doi.org/10.1016/j.eurpolymj.2008.03.018

For more information about UCLan's research in this area go to http://www.uclan.ac.uk/researchgroups/ and search for < name of research Group $>$.

For information about Research generally at UCLan please go to http://www.uclan.ac.uk/research/

All outputs in CLoK are protected by Intellectual Property Rights law, including Copyright law. Copyright, IPR and Moral Rights for the works on this site are retained by the individual authors and/or other copyright owners. Terms and conditions for use of this material are defined in the policies page.

\section{CLoK}

Central Lancashire online Knowledge www.clok.uclan.ac.uk

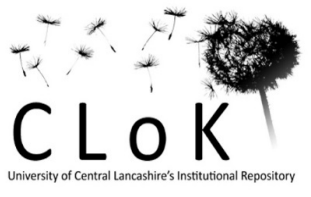




\title{
Characterisation of the dispersion in polymer flame retarded nanocomposite
}

\author{
F. Samyn, ${ }^{1}$ S. Bourbigot,${ }^{1}$ C. Jama, ${ }^{1}$ S. Nazare, ${ }^{2}$ B. Biswas, ${ }^{2}$ R. Hull, ${ }^{2}$ A. Fina, ${ }^{3}$ A. \\ Castrovinci, ${ }^{3}$ G. Camino, ${ }^{3}$ M. Hagen ${ }^{4}$ M. Delichatsios ${ }^{4}$ \\ ${ }^{1}$ LSPES, Procédés d'Elaboration de Revêtements Fonctionnels, LSPES - UMR 8008, \\ ENSCL, BP 90108, 59652 Villeneuve d'Ascq, France \\ ${ }^{2}$ Centre for Materials Research and Innovation, Bolton University, Deane Campus, Bolton, \\ BL3 5AB (England) \\ ${ }^{3}$ Centro Ingegneria Materie Plastiche, V.le Teresa Michel, 5, 15100 Alessandria (Italy) \\ ${ }^{4}$ FireSERT, Ulster University of Jordanstown, Newtownabbey, County Antrim, BT370QB \\ (Northern Ireland)
}

Corresponding author: serge.bourbigot@ensc-lille.fr, tel: 03204348 88, fax: 0320436584 


\begin{abstract}
:
Flame retardant nanocomposites have attracted many research efforts because they combine the advantages of a conventional flame retardant polymer with that of polymer nanocomposite. As a bonus it leads very often to a synergistic effect. However the properties obtained depend, as for classical nanocomposites, on the dispersion of the nanoparticles. In this study, three types of polymer flame retarded nanocomposites based on different matrices (PP, PBT and PA6) have been prepared by extrusion. Then the tools usually used to characterise the morphology of composites have been evaluated on such composites to check the validity of the measurements. In the case of XRD and TEM, useful information has been obtained to describe the dispersion of the flame retarded nanocomposite. It appears that the material based on PA6, OP1311 and C30B has a great dispersion of the platelets. In the two other systems PBT and PP materials, microcomposites are obtained with some extent of intercalation. The poor dispersion is also highlighted by NMR measurements but the presence of flame retardant particles interferes in the quantitative evaluation of the dispersion. Melt rheology has as been used as a characterisation technique to assess the dispersion and lead to results coherent with the XRD and TEM conclusions.
\end{abstract}

Key words: TEM, X-ray diffraction, solid state NMR, Rheology, PA6, PBT, PP, flame retarded nanocomposite 


\section{Introduction}

Different strategies can be used to improve the flammability properties of polymeric materials. The incorporation of specific additives constitutes a very interesting route. Classically the first approach consists in addition of flame retardant additives in the polymeric matrix. These additives will act either chemically or physically, in the gas phase or the condensed phase, to inhibit or suppress the combustion process. Different classes of flame retardants can be used such as halogenated compounds, metal hydroxides or intumescent formulations. This last class of flame retardant exhibit some advantages compared with the two other class of flame retardant. The efficiency of such systems is obtained at very reasonable contents (around 25\%) what does not affect too much, the other properties in contrary to metal hydroxide that have to be incorporated at up to $60 \mathrm{wt} .-\%$. Moreover such systems suit well to the growing demands of industrials to develop halogen free solutions in terms of fire protection.

Two other methods have been more recently investigated based on the nanocomposite approach. The first one has been developed in the past 30 years. It is the incorporation of nanoparticules in the polymer. Different shapes of particles can be used (spherical such as silica, nanotubes or nanofibres such as carbon nanotubes, lamellar or platelets such as montmorillonite ...) but at least one dimension of the particle has to be lower than $100 \mathrm{~nm}$. Most of the studies reported in the literature concern polymer-layered silicate nanocomposites (PLSNC). This article is focused on this kind of nanocomposites. Generally for nanodispersed composites, improved fire properties are obtained with less than $10 \%$ of nanoparticules and improvements of other properties are simultaneously observed. The mechanism via which the reaction to fire is modified can be attributed to the accumulation of inorganic particles at the surface of the composite and concurrently, to the formation of a carbonaceous coating forming a barrier to heat and mass transfers.

More recently, a derived approach has emerged. This approach consists in the development of polymer flame retarded layered silicate nanocomposites (PFRLSNC). In this route, both classical flame retardant and nanoparticules are added in the polymer to research potential synergistic effects. In the past 10 years, an increasing number of studies deals with that topic. Combinations of intumescent compounds and organoclay have for example been studied by Bourbigot and $\mathrm{Al}^{1}{ }^{2}$. They reported the performances of PA6 nanocomposite as char forming agent in intumescent formulations and as mechanical reinforcement agent. Other types of flame retarded nanocomposite have already been studied. The fire performances of 
$\mathrm{EVA}+\mathrm{Al}(\mathrm{OH})_{3}$ with nanoparticles are significantly enhanced ${ }^{3}$. As for the polymer clay nanocomposite, it could be assumed that the dispersion of the nanoparticles in the polymer flame retarded nanocomposites is a key factor to obtain the best properties. However not much has been published on how to characterize the morphology of this type of composites and on the relative location of platelets and flame retardant particles.

In a previous paper ${ }^{4}$, PLSNC based on PA6, PBT and PP matrices have been fully characterised in terms of dispersion of clay platelets using XRD, TEM, melt rheology and NMR techniques. The efficiency of each method to describe the composite structure has been evaluated and compared to each other. In this study, using the three matrices quoted before, PFRLS nanocomposites have been prepared using commercial phosphorous flame retardant systems. A characterisation of morphology of the composite obtained has been undertaken using XRD, SEM, TEM, melt rheology and NMR measurements. The global aim of this study is to examine the validity of methods applied for characterizing the morphology of the PLS nanocomposites in the case of PFRLSNC and to evaluate the influence of addition of the flame retardant on the structure of the composites obtained.

\section{Experimental}

\subsection{Materials}

Table 1 summarizes the materials used in this work as well as the suppliers of the products and the chemical formula.

Table 1 : materials

\begin{tabular}{|c|c|c|c|c|}
\hline Product & Abbreviation & Supplier & Reference & Formula \\
\hline Polyamide 6 & PA6 & Rhodia & $\begin{array}{c}\text { Technyl } \\
\text { S27 }\end{array}$ & \\
\hline Polypropylene & PP & Basell & $\begin{array}{l}\text { Molpen } \\
\text { HO500N }\end{array}$ & \\
\hline $\begin{array}{c}\text { Polypropylene } \\
\text { grafted maleic } \\
\text { anhydride }\end{array}$ & Polybond & Crompton & $\begin{array}{c}\text { Polybond } \\
3200\end{array}$ & \\
\hline
\end{tabular}




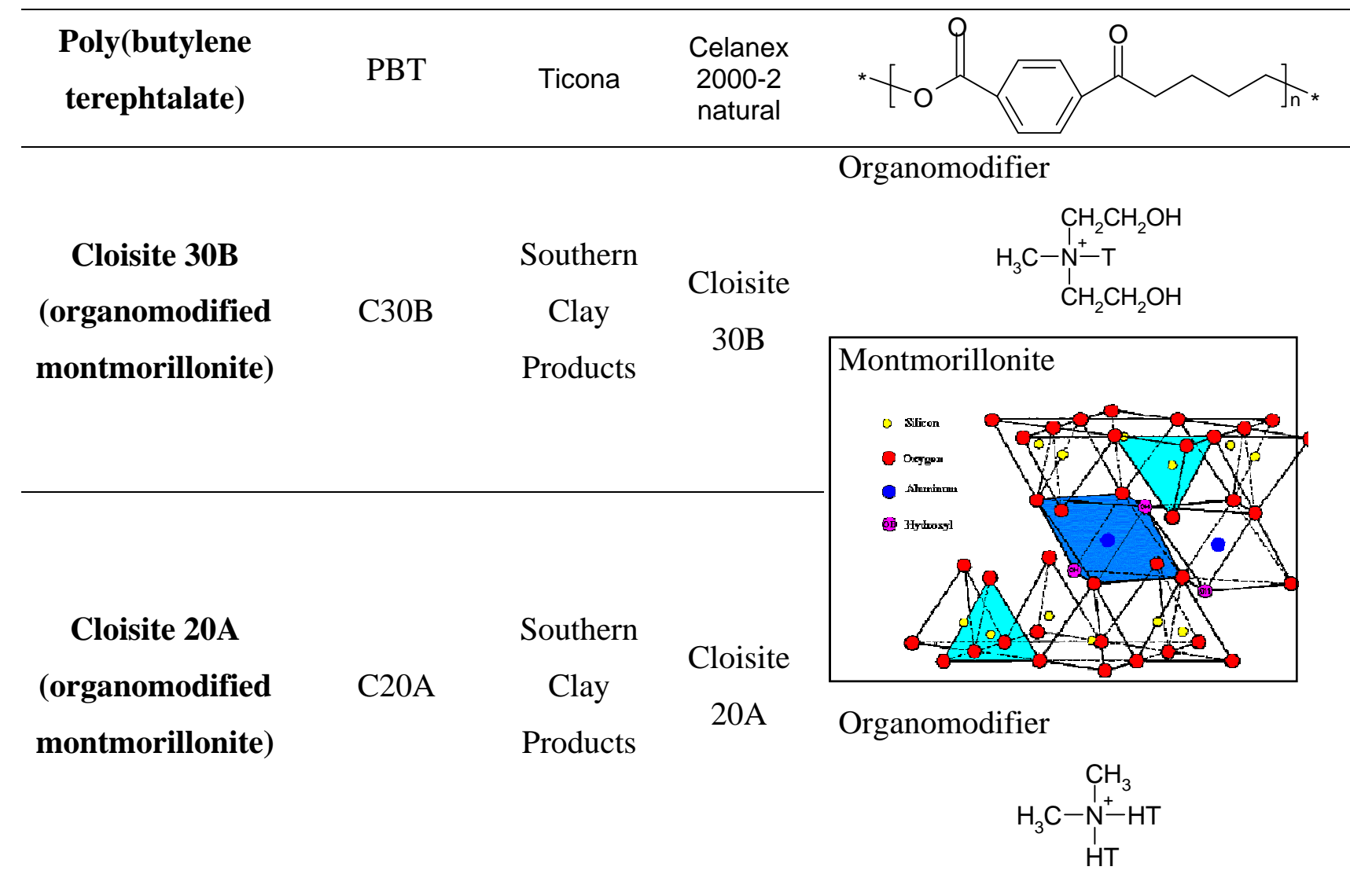

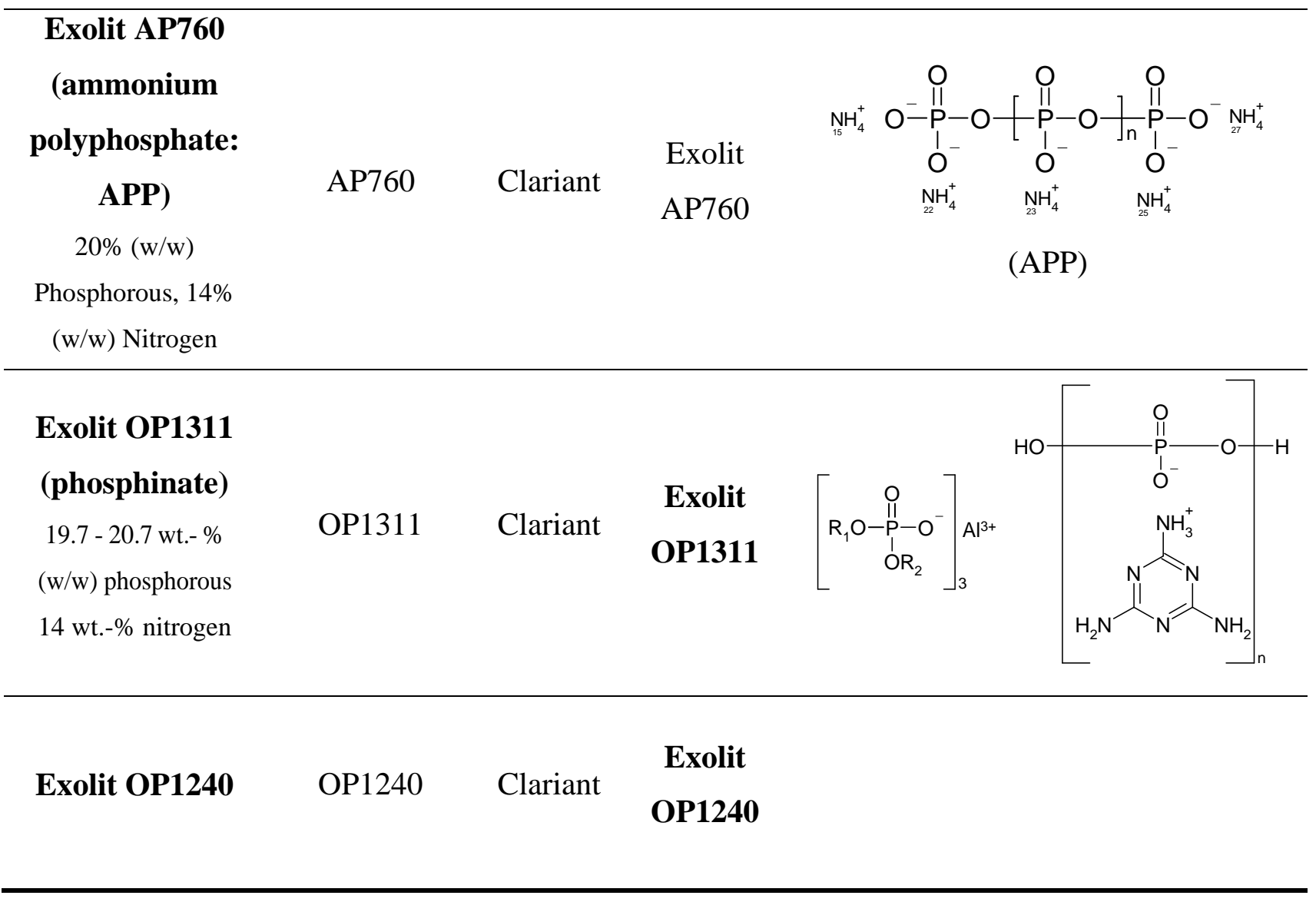




\subsection{Samples preparation}

The materials (Table 2) were prepared by melt blending using an American Leistritz Extruder Model ZSE 27. This extruder has a $27 \mathrm{~mm}$ co-rotating intermeshing twin screw with 10 zones and a length/diameter ratio of 40 . The extruder design and the temperature profile are given in Figure 1 and Table 3 . The polymer pellets were introduced in the first zone. For PP materials, APP is added in the main feed (same position as PP), by means of a dedicated gravimetric feeder and the nanofiller in the third zones with a side gravimetric feeder (screw speed 180 rpm). In the case of PA6 and PBT, OP is added in the side feeder, together with the clay, previously mechanically mixed. For all the formulations, both the flame retarded polymer and the polymer flame retarded nanocomposite materials were prepared using this device with a screw speed of $200 \mathrm{rpm}$ and a feed rate of $10 \mathrm{~kg} / \mathrm{h}$. The material obtained is then pelletized.

Table 2 : Formulations prepared

\begin{tabular}{|l|c|c|c|}
\cline { 2 - 4 } \multicolumn{1}{c|}{} & $\begin{array}{c}\text { Polymer } \\
(\text { wt.- } \%)\end{array}$ & $\begin{array}{c}\text { FR } \\
\text { (wt.-\%) }\end{array}$ & $\begin{array}{c}\text { NC (wt.-\%) } \\
\text { (OM-MMT) }\end{array}$ \\
\hline PBT & 100 & & \\
\hline PBT + OP1240 & 90 & 10 & \\
\hline PBT + OP1240 + Cloisite 30B & 85 & 10 & 5 \\
\hline PP polybond & 100 & & \\
\hline PP polybond+ AP760 & 70 & 30 & \\
\hline PP polybond + AP760 + C20A & 65 & 30 & 5 \\
\hline PA6 & 100 & & \\
\hline PA6 + OP1311 & 82 & 18 & 5 \\
\hline PA6 + OP1311 + C30B & 77 & 18 & 5 \\
\hline
\end{tabular}

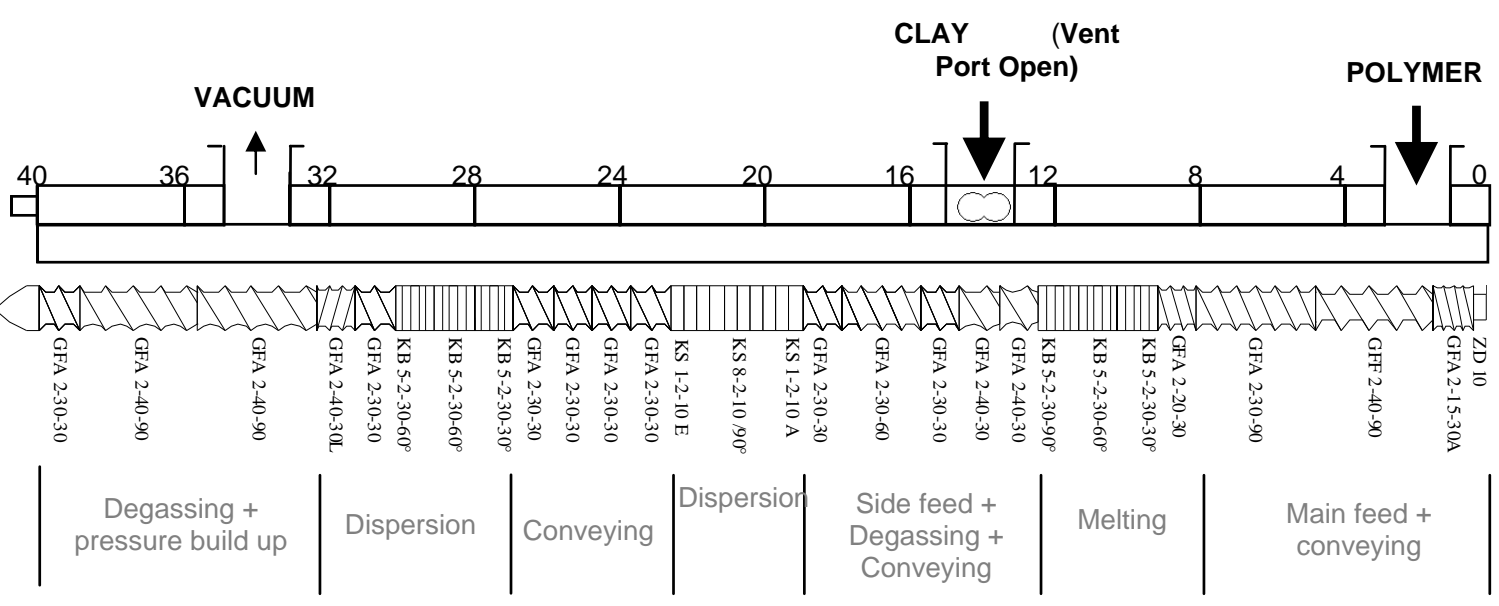

Figure 1: Screw design 
Table 3 : temperature profile for the three types of formulations

\begin{tabular}{ccccccccccc}
\hline & Zone 10 & Zone 9 & Zone 8 & Zone 7 & Zone 6 & Zone 5 & Zone 4 & Zone 3 & Zone 2 & Zone 1 \\
& 36-40D & 32-36D & $28-32 \mathrm{D}$ & $24-28 \mathrm{D}$ & $20-24 \mathrm{D}$ & $16-20 \mathrm{D}$ & $12-16 \mathrm{D}$ & 8-12D & $4-8 \mathrm{D}$ & $0-4 \mathrm{D}$ \\
\hline PA6 & 250 & 250 & 250 & 245 & 245 & 245 & 240 & 240 & 240 & 250 \\
\hline PBT & 255 & 255 & 255 & 245 & 245 & 245 & 240 & 240 & 240 & 250 \\
\hline PP & 230 & 230 & 230 & 220 & 220 & 220 & 210 & 210 & 210 & 220 \\
\hline
\end{tabular}

\subsection{Characterisation}

\subsubsection{X-ray diffraction (XRD)}

XRD analyses were conducted at ambient temperature using a Philips X'Pert X-ray diffractometer $\left(\left(\lambda\left(\mathrm{Cu}_{\mathrm{K} \alpha}\right)=1.540562 \AA\right)\right.$ in configuration 2-theta/ theta on slabs of materials. XRD spectra were recorded in the $1.5^{\circ}-10^{\circ} 2 \theta$ range with a step of $0.02^{\circ}$, a step time of $2.5 \mathrm{~s}$. The interlayer spacing $\mathrm{d}$ was deduced from the recorded data.

\subsubsection{Rheology}

Rheological measurements were carried out at Dynamic Analyser Rheometer RDA II from Rheometrics. Parallel plate geometry with a plate diameter of $25 \mathrm{~mm}$ was used. Thin films of materials of $1 \mathrm{~mm}$ thickness were used to perform the tests. To ensure the viscoelastic region, linear rheological measurements were performed at a frequency range of 0.1 to $100 \%$. Complex viscosities $\left(\eta^{*}\right)$ was obtained at $240^{\circ} \mathrm{C}$. The temperature control was accurate to within $\pm 1^{\circ} \mathrm{C}$. Experiments were conducted under a nitrogen atmosphere in order to avoid oxidative degradation of the specimen.

A schematic diagram of the rheometer in the parallel plate configuration is shown in Figure 2.

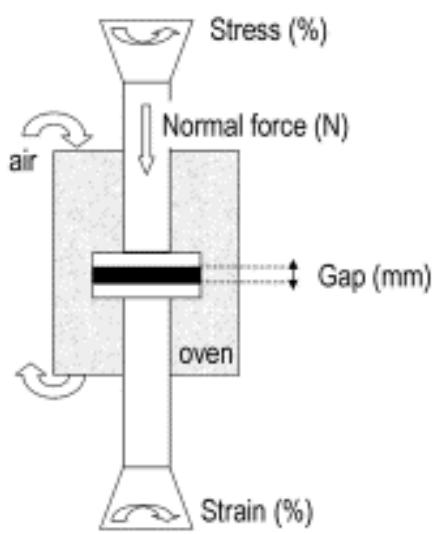

Figure 2 : Schematic of rheometer in the parallel plate configuration 
The complex viscosity results have been analysed according to the method developed by Wagener and Reisinger ${ }^{5}$ so that the shear thinning exponent $n$ was determined. In this case the behaviour of the nanocomposite is compared to the behaviour of the flame retarded polymer considered as the matrix.

\subsubsection{Solid state nuclear magnetic resonance}

Deoxygenated granular samples were prepared by pumping at high vacuum for $2 \mathrm{~h}$ at $60{ }^{\circ} \mathrm{C}$ in 5-mm o.d. glass tubes and sealing the tubes. Measurements were conducted using a Bruker Avance 400 spectrometer (at Larmor frequency of proton of $400 \mathrm{MHz}$ ). $\mathrm{T}_{1}{ }^{\mathrm{H}}$ recovery curves were then measured with the saturation-recovery sequence with direct proton observation. Three closely spaced $90^{\circ}$ pulses accomplished the saturation.

As a semi empirical approach to analysis, these saturation-recovery curves were fit to a two-exponential equation according to:

$$
\mathrm{M}(\mathrm{t})=\mathrm{M}_{0 \mathrm{~S}}\left(1-\mathrm{e}\left(-\mathrm{t} / \mathrm{T}_{1 \mathrm{~s}}{ }^{\mathrm{H}}\right)\right)+\mathrm{M}_{01}\left(1-\mathrm{e}\left(-\mathrm{t} / \mathrm{T}_{11}{ }^{\mathrm{H}}\right)\right)
$$

where $\mathrm{M}(\mathrm{t})$ is the magnetization at time $\mathrm{t} ; \mathrm{M}_{0 \mathrm{~s}}$ and $\mathrm{M}_{01}$ are the magnetization of the short and long components, respectively, and; $\mathrm{T}_{1 \mathrm{~s}}{ }^{\mathrm{H}}$ and $\mathrm{T}_{11}{ }^{\mathrm{H}}$ are the proton longitudinal relaxation times of the short and long components, respectively.

The equation was fitted with the commercial program TableCurve2D of Jandel Scientific with a standard least-squares minimization (Gaussian elimination). The accuracy of the fit was evaluated by an analysis of residuals in a $95 \%$ confidence domain. All fitted values of $\mathrm{T}_{11}{ }^{\mathrm{H}}$ and $\mathrm{T}_{1 \mathrm{~s}}{ }^{\mathrm{H}}$ had 3 and $5 \%$ standard uncertainties, respectively. Corresponding standard uncertainties for the two $\mathrm{M}_{0}$ 's were typically less than $5 \%$.

The quantitative NMR method developed by Bourbigot and $A l^{6}$ has been designed to characterize the dispersion of nanoclay in a polymer matrix. In this work, we applied this method to more complicated systems considering that the polymeric matrix is in this case the Flame retarded polymer. Two parameters characteristic of the dispersion state will be calculated what will enables to quantify both the degree of separation of the platelets (factor $\mathrm{f}$ measuring the polymer/clay interfaces) and the homogeneity of the dispersion (factor e). For the calculations, the flame retarded polymer has been considered as the reference materials, as the matrix in which the nanoclay has been dispersed. 


\subsubsection{Microscopy}

Surface microscopic analyses were carried out on a scanning electron microscope (SEM) Hitachi S4700 at $6 \mathrm{kV}$ and $15 \mathrm{~mA}$ at various levels of magnification.

For Transmission electron spectroscopy analyses, all samples were ultra microtomed with a diamond knife on a Leica ultracut UCT microtome, at room temperature for PP, PBT samples and at cryo temperature $\left(-120^{\circ} \mathrm{C}\right)$ for PA6 samples, to give sections with a nominal thickness of $70 \mathrm{~nm}$. Sections were transferred to $\mathrm{Cu}$ grids of 400 meshes. Bright-field TEM images of nanocomposites were obtained at $300 \mathrm{kV}$ under low dose conditions with a Philips CM30 electron microscope, using a Gatan CCD camera. Low magnification images were taken at 17 000x and high-magnification images were taken at 100 000x.

The materials were sampled by taking several images of various magnifications over 2-3 sections per grid to ensure that analysis was based on a representative region of the sample.

EDX microanalyses were performed with a FEI Tecnai G2 20 transmission electron microscope at $200 \mathrm{kV}$.

\section{Results}

The purpose of this study is to investigate the dispersion of the nanoparticules in flame retarded polymer from the microscale to the nanoscale. Firstly SEM analyses have been performed to get an overview of the dispersion of clay platelets as well as for detecting potential large tactoids. Then XRD, melt rheology and NMR measurements have been undertaken to characterize the morphology of nanocomposite. Finally to have a precise view of the materials at the nanoscale and to discuss the conclusions deduced from the other techniques, TEM observations have been done.

\subsubsection{SEM}

SEM observation of the flame retarded PA6 nanocomposite material has been undertaken (Figure 3). It shows that there are some agglomerated particles and more dispersed ones. EDX analysis of the particles has identified phosphorous species in there and thus; these particles can be attributed to the flame retardant. However, tactoids of $\mathrm{NC}$ are not detected by this 
picture what suggests that no agglomerates of clay of a size above a few micrometers are formed.

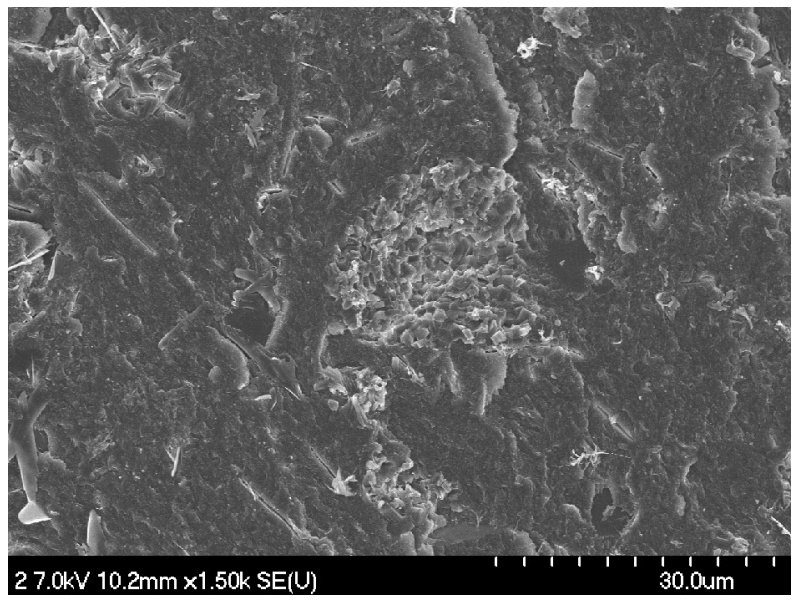

Figure 3: SEM micrograph of the material containing PA6 + FR + NC

Figure 4 and Figure 5 shows respectively micrographs of the PBT flame retarded composite and PP flame retarded composite at different magnifications. Agglomerated particles (about $100 \mu \mathrm{m}$ for PBT and about $20 \mu \mathrm{m}$ for PP) of FR are detected as well as smaller ones of a few micrometers. The clay is not observed on these pictures. It suggests therefore that the clay dispersion is submicronic.

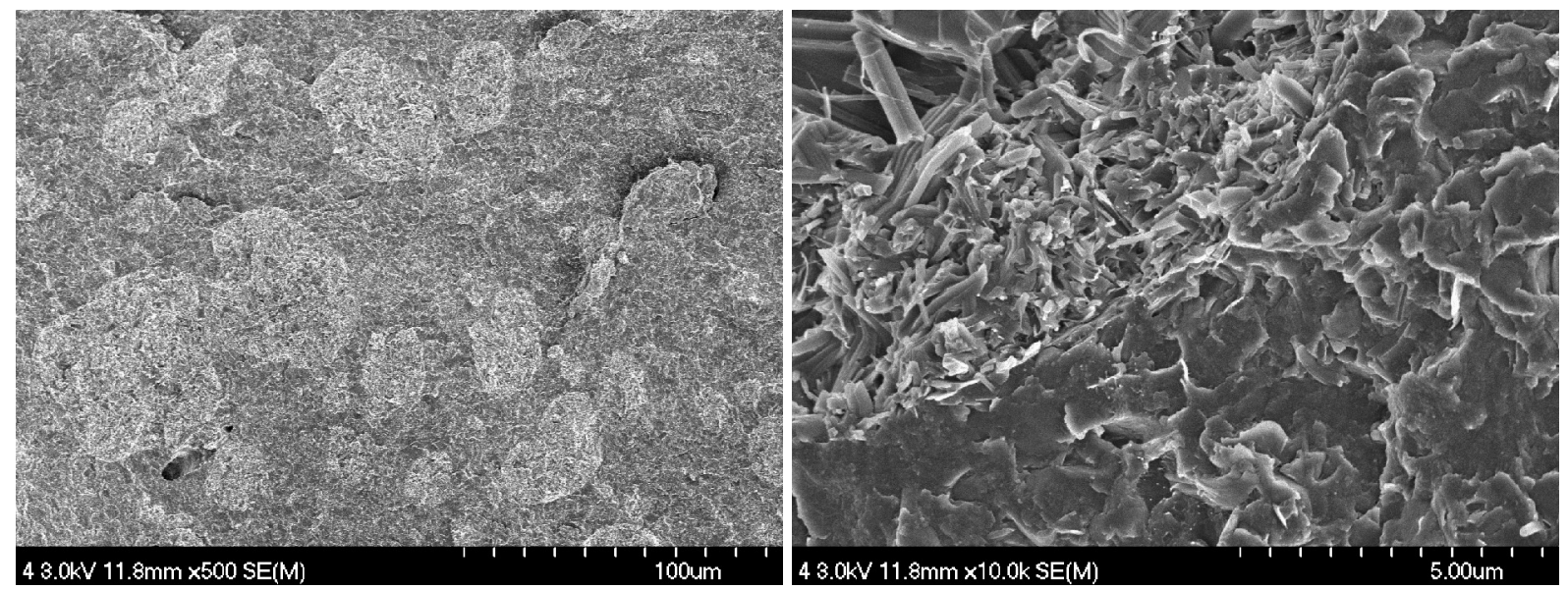

Figure 4: SEM micrographs of the material containing PBT + FR + NC at different magnifications 

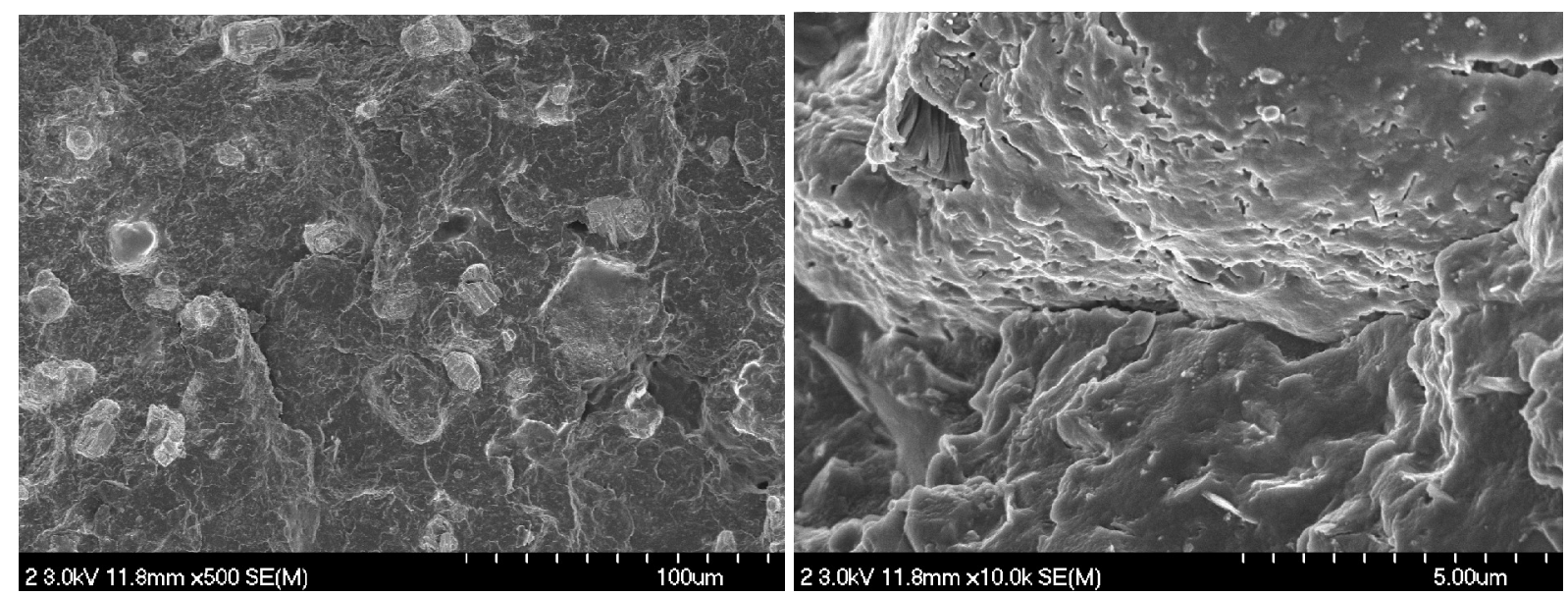

Figure 5: SEM micrographs of the material containing PP + FR + NC at different magnifications

\subsubsection{XRD}

Figure 6 shows the XRD results for Cloisite C30B and PA6 and PBT flame retarded composites. For PA6, the peak characteristic of the $\mathrm{d}_{001}$ of Cloisite C30B disappears for the nanocomposite material. This suggests that an exfoliated morphology is obtained. For PBT flame retarded nanocomposite, the presence of a peak at 2 theta $=4.6^{\circ}$ is observed. For the neat Cloisite $30 \mathrm{~B}$, the peak is at $4.7^{\circ}$ suggesting low intercalation of PBT chains in clay galleries and poor dispersion in the polymer.

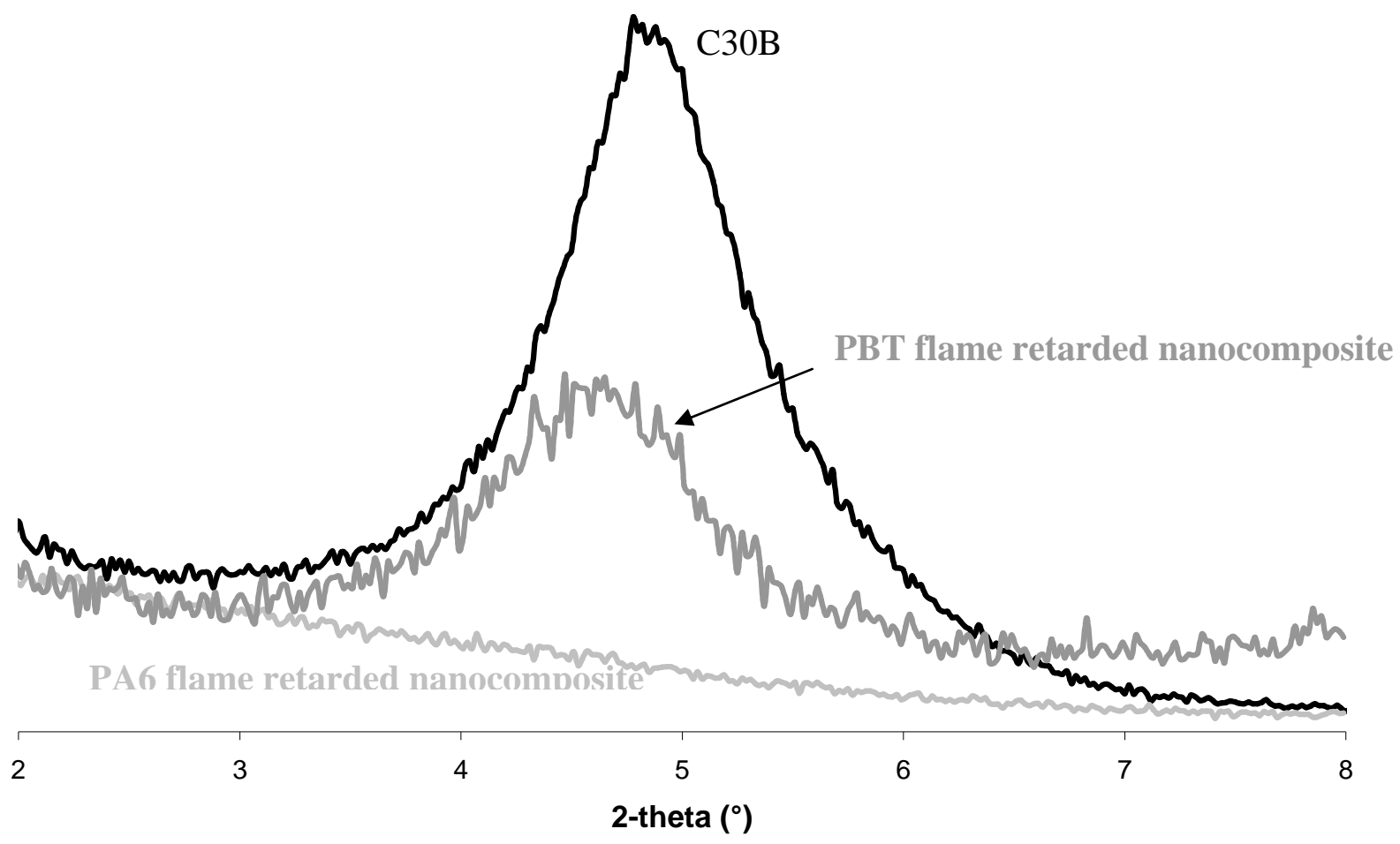

Figure 6: XRD spectra of C30B and PA6 and PBT flame retarded composites 
XRD analysis of the PP flame retarded composite has been performed (Figure 7). The comparison of the spectrum with the one of the neat Cloisite 20A shows that there is a shift from $3.6^{\circ} 2$-theta for the neat clay to $2.65^{\circ} 2$-theta. This suggests that there is intercalation of the platelets with a d-spacing $33,3 \AA$.

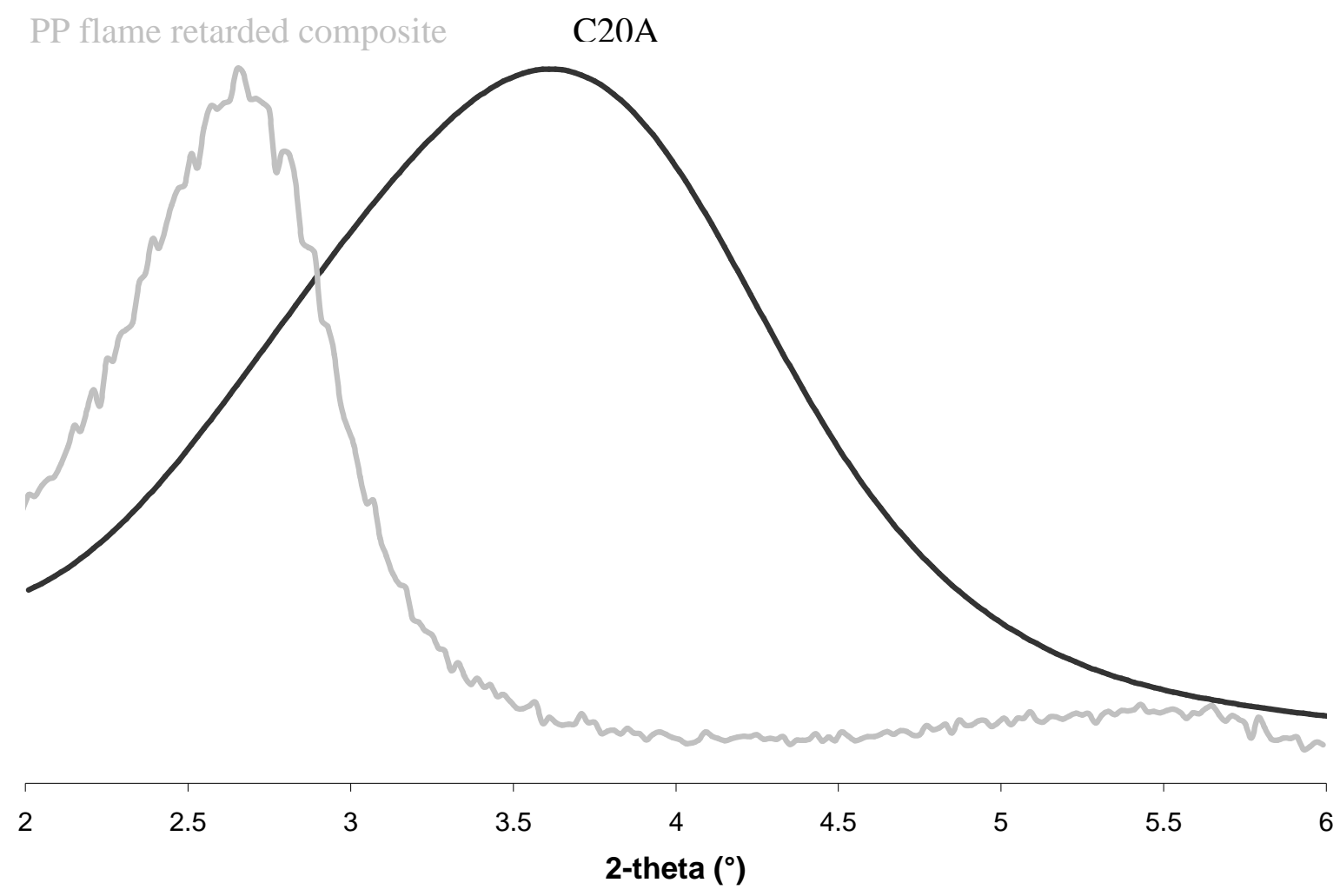

Figure 7: PP + 30\%-wt. Flame retardant + 5\%-wt. Clay

\subsubsection{Melt rheology}

Figure 8 presents the complex viscosity curve of PA6 materials. The presence of nanoclay in the PA6 flame retarded formulation causes an important increase of the viscosity at low frequency and then a shear thinning behaviour is observed versus the frequency $(\eta=-0.56)$. It gives therefore evidence of the correct dispersion of the clay into the flame retarded PA6 matrix. 


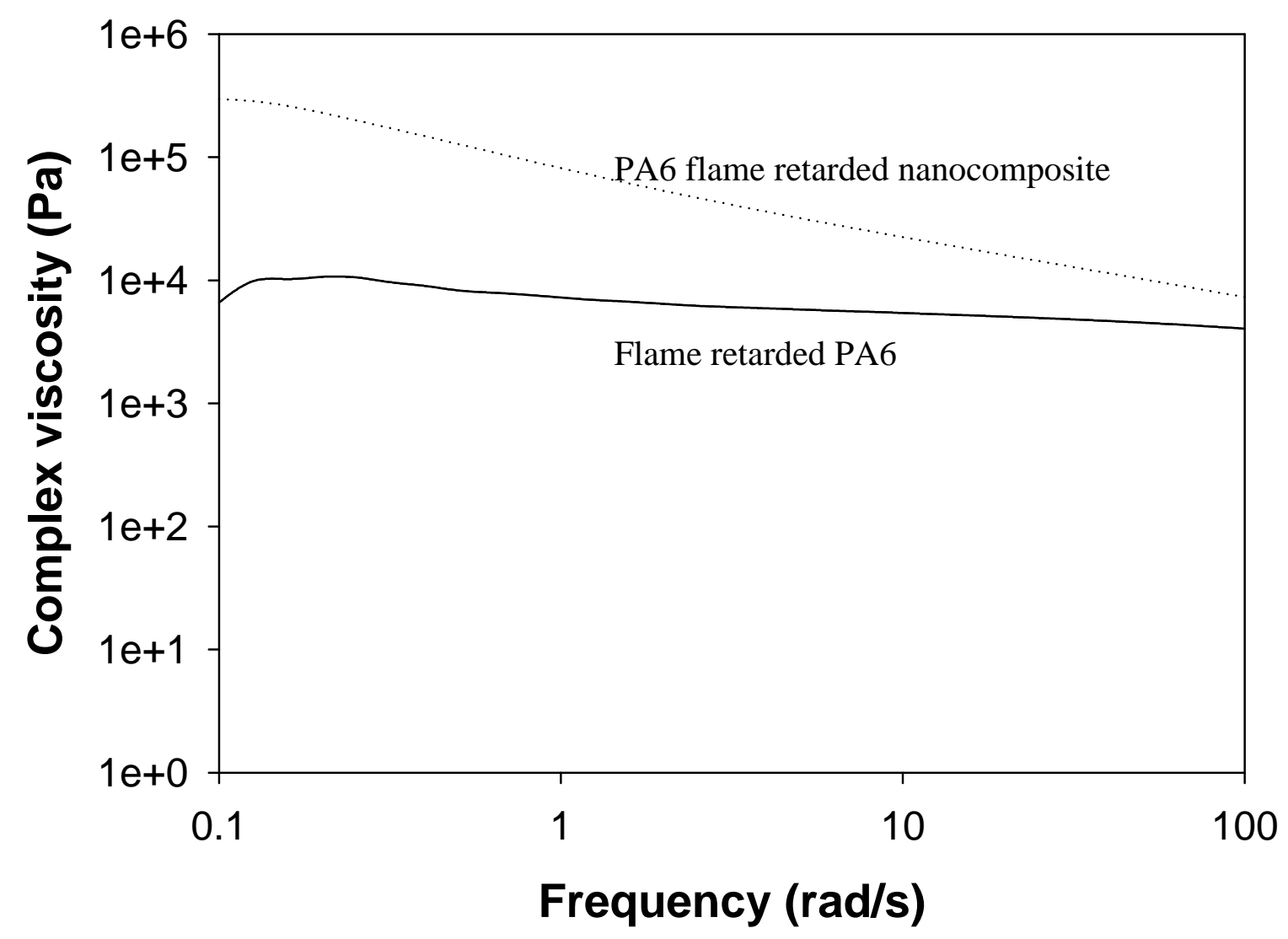

Figure 8: Complex viscosity curves for pure flame retarded PA6 and its composite

Figure 9 shows complex viscosity curves for PBT formulations. PBT flame retarded nanocomposite shows non-Newtonian behaviour in the low frequency region and pronounced shear thinning at higher frequencies $(\eta=-0.65)$. Significant increase in zero shear viscosity and pronounced shear thinning at low loading levels of 5\% is a characteristic feature of nanocomposite structure. 


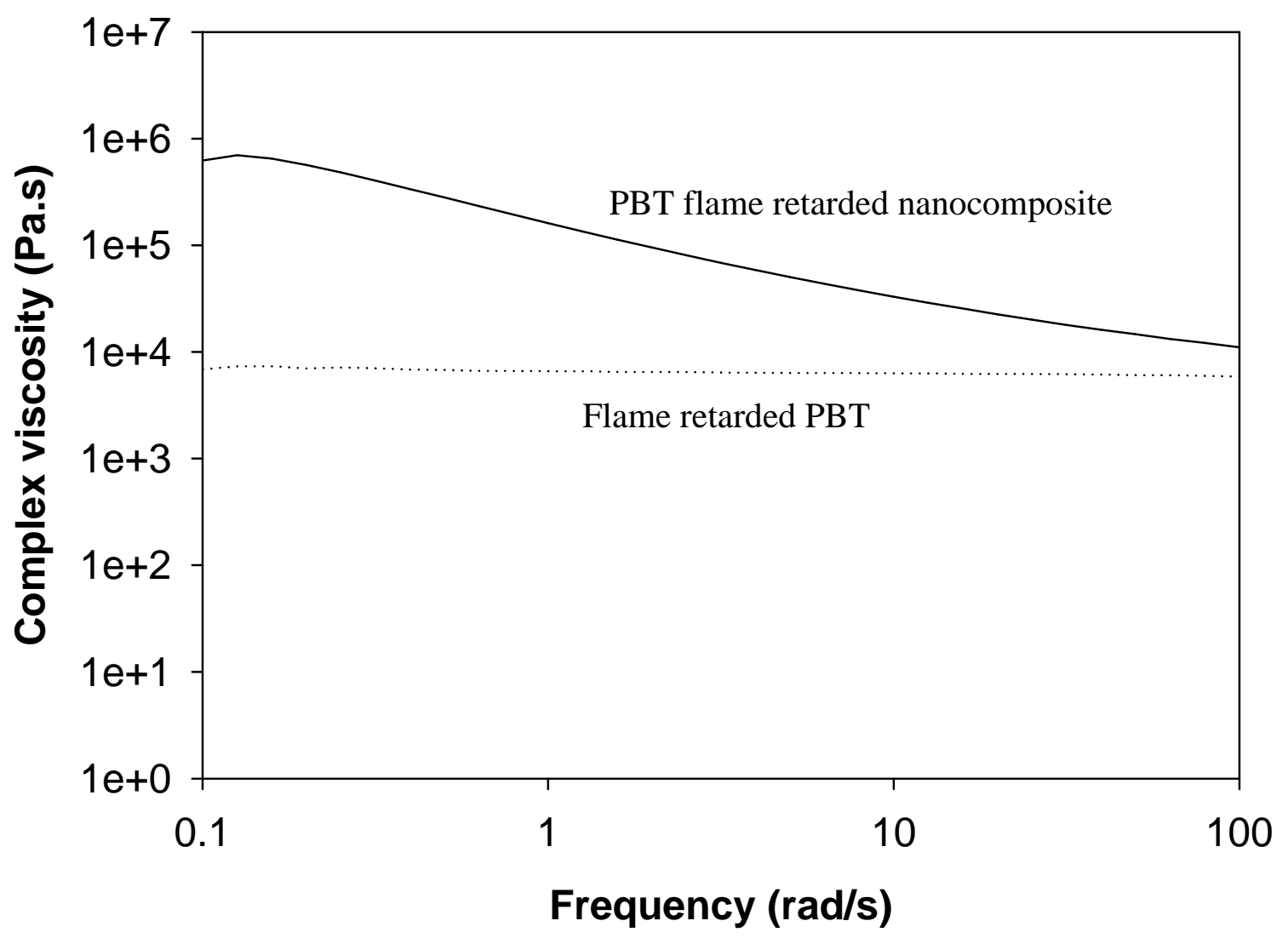

Figure 9: Complex viscosity curves for pure PBT + FR and PBT + FR + NC

Complex viscosity curves for the PP FR nanocomposite in Figure 10 shows significant increase in complex viscosity compared with flame retarded PP. Moreover, at higher frequencies, there is some amount of shear thinning (shear thinning component $\eta=-0.44$ ). This rheological behaviour suggests that there is increased intercalation of polymer chains between the clay platelets however, the mixture has not yet reached a percolation threshold which results in pronounced shear thinning. 


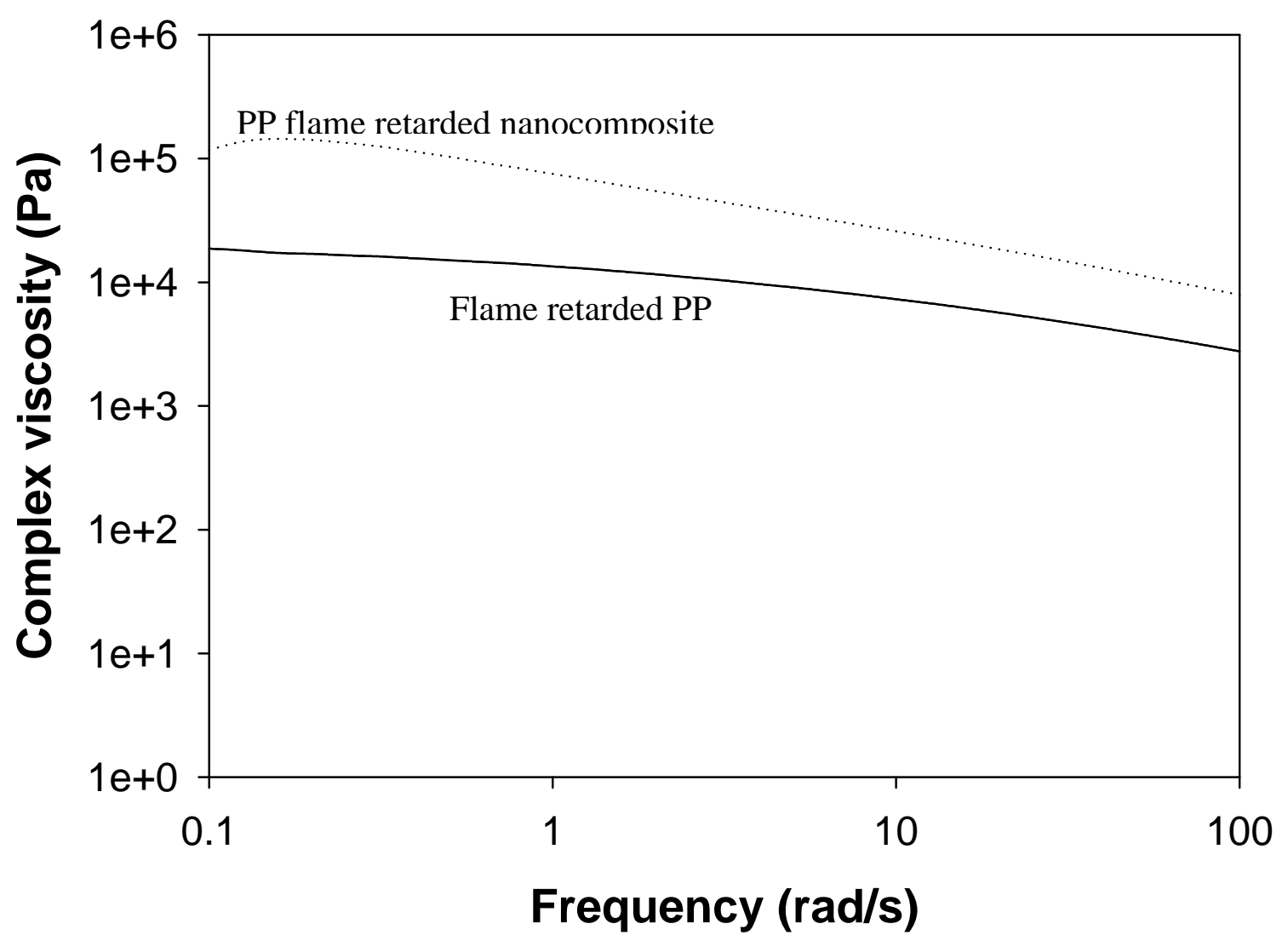

Figure 10: Complex viscosity curves for pure PP and its composites

\subsubsection{Solid state NMR}

$\mathrm{T}_{1}{ }^{\mathrm{H}}$ values have been calculated by fitting the experimental data obtained for each flame retarded polymer and nanocomposite with a biexponential. The values are gathered in Table 4. As expected, the presence of clay shortens the relaxation time in the case of PA6 and PBT nanocomposites because of the paramagnetically induced relaxation at the polymer-clay interface (from $1.87 \mathrm{~s}$ for pure PA6 to $1.13 \mathrm{~s}$ for PA6/OP1311/C30B, from $2.46 \mathrm{~s}$ for pure PBT to $1.16 \mathrm{~s}$ for PBT/OP1240/C30B and from $1.52 \mathrm{~s}$ for pure PP to $1.15 \mathrm{~s}$ for $\mathrm{PP} / \mathrm{AP760/C30B}$ ) what indicates that some extent of clay dispersion is achieved.

The spin diffusion model has been applied to obtain a quantitative description of the dispersion assuming that FR polymer may be taken as reference (sample without clay) to make our calculations.

The first part (at the very earliest times) of the total spin magnetization curve is related to the polymer-clay interfacial area available in the matrix, or in other words, the initial slope of the 
curve is proportional to the polymer-clay interface concentration. Curves of Figure 16 show that the experimental magnetizations exhibit a reasonably linear dependence vs. the square root of the time $(10 \mathrm{~ms}<\mathrm{t}<60 \mathrm{~ms})$ for the three nanocomposites.

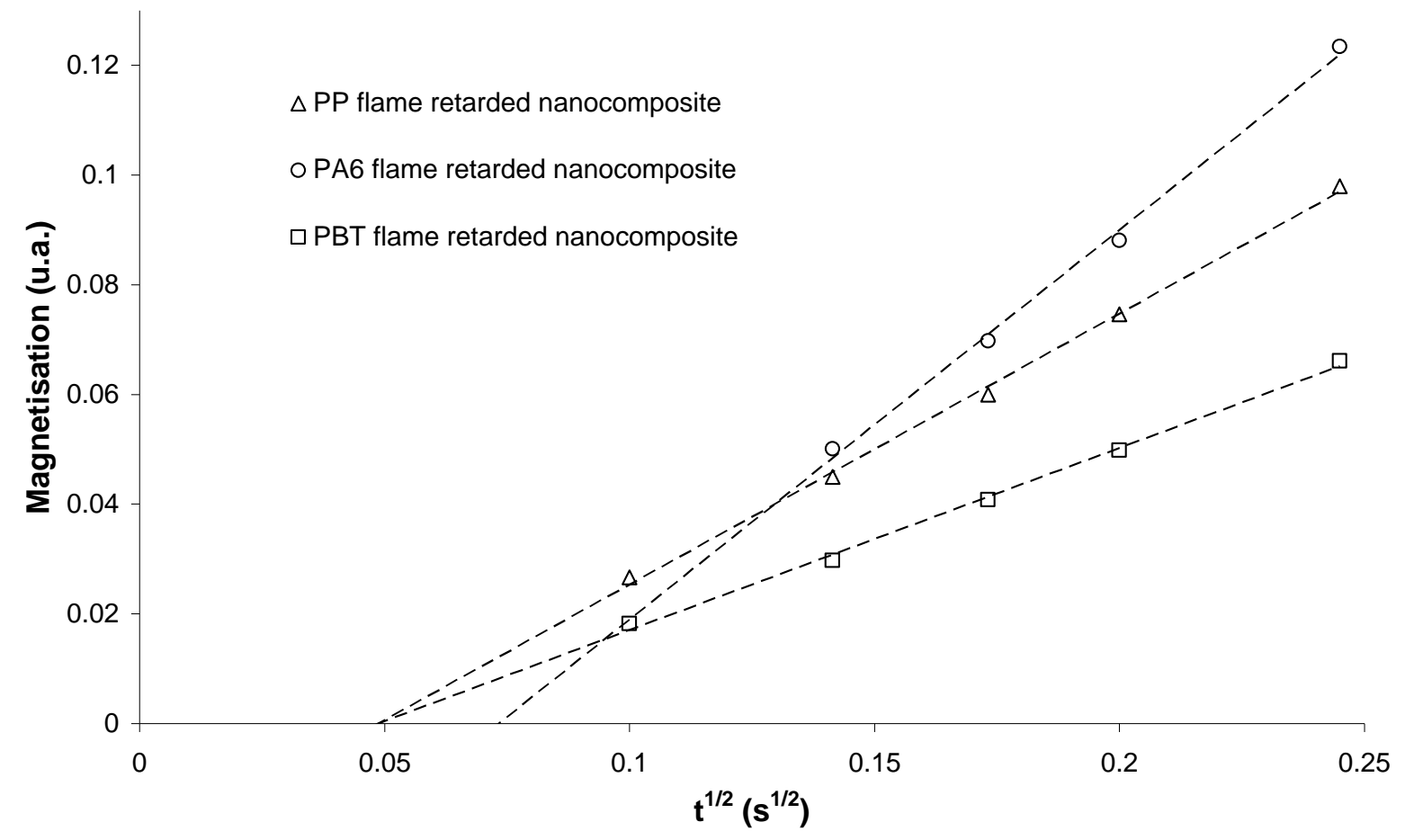

To calculate the fraction of the effective polymer-clay interfacial area, $f$, from the initial slopes, we need to choose a reference sample which exhibits a fully exfoliated structure. As in our previous work [17], we used a PS/MMT nanocomposite where the organo-modifier of MMT was N,N-dimethyl-n-hexadecyl-(4-vinylbenzyl) ammonium chloride (VB16) and hereafter called PS/VB16 [12]. We also stated that $\mathrm{T}_{11}{ }^{\mathrm{H}}$ is a relative indicator of the homogeneity of the distribution of the actual polymer-clay interfaces in the nanocomposite. We can compute, using our model calculation, an apparent spacing, $\Delta$ app that matches the $\mathrm{T}_{11}{ }^{\mathrm{H}}$ obtained from the experimental curves. We can then compare $\Delta \mathrm{app}$ with $\Delta \mathrm{f}$, the spacing in an ideally layered structure that has a surface area $\mathrm{f}$ times the amount expected from full exfoliation. Thus, we define a parameter, $e=\Delta f / \Delta a p p$, to be a qualitative monitor of the inhomogeneity of the distribution of clay where poor homogeneity would correspond to $e=1$.

According to the results presented in table 4, the clay seems to be not very well dispersed in the flame retarded polymeric matrices. The materials would exhibit an intermediate homogeneity (between 29 and 58\%) but the f values are poor suggesting the presence of numerous tactoïdes and poor dispersion for all materials. 
Table 4: NMR parameters for the characterization of the dispersion of all the materials

\begin{tabular}{|c|c|c|c|}
\hline Material & $\mathrm{T}_{11}{ }^{\mathrm{H}}$ & $\mathrm{f}$ & $\mathrm{e}(\%)$ \\
\hline PA6 + FR & 1.87 & & \\
\hline PA6 + FR + NC & 1.13 & 0.39 & 50 \\
\hline PBT + FR & 2.46 & & \\
\hline PBT + FR + C30B & 2.16 & 0.11 & 29 \\
\hline PP + FR & 1.52 & & \\
\hline PP + FR + NC & 1.15 & 0.08 & 58 \\
\hline
\end{tabular}

\subsubsection{TEM}

Figure 11 shows TEM pictures of the PA6 flame retarded nanocomposite. The exfoliation of the clay is clearly evidenced by these pictures. Single platelets are meanly encountered in the sample and only a few small tactoids of 2 or 3 platelets have been detected. With the picture at high magnification we can see that the dispersion is not perfectly homogeneous: some part of the sample presenting a higher concentration of platelets.
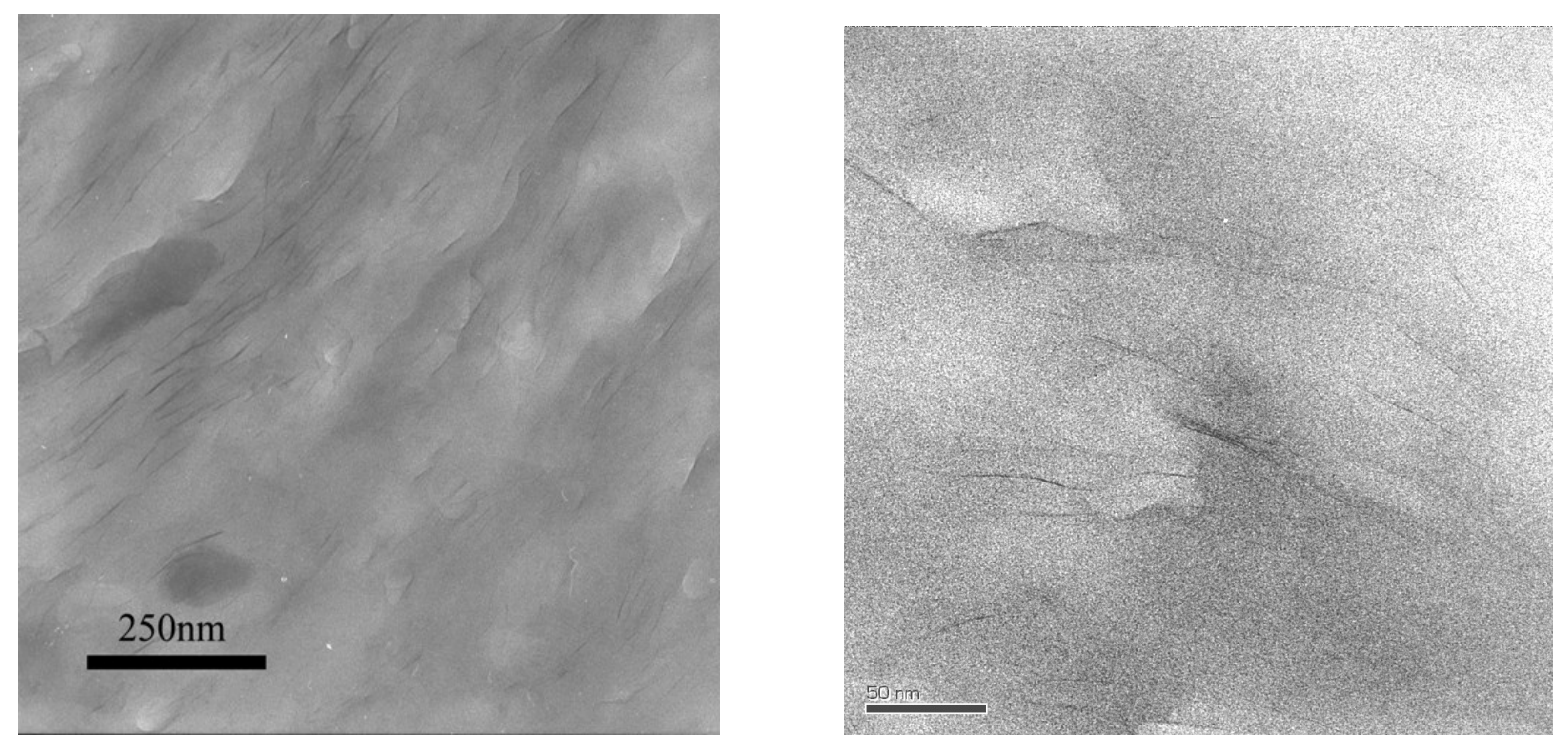

Figure 11 : TEM picture of PA6 flame retarded nanocomposite at different magnifications

TEM analyses of the PBT flame retarded nanocomposite have been carried out to observe the dispersion of the platelets in the matrix. At low magnification, big agglomerates of different sizes are observed. The micrograph at high magnification reveals that some extents of intercalation is obtained. 

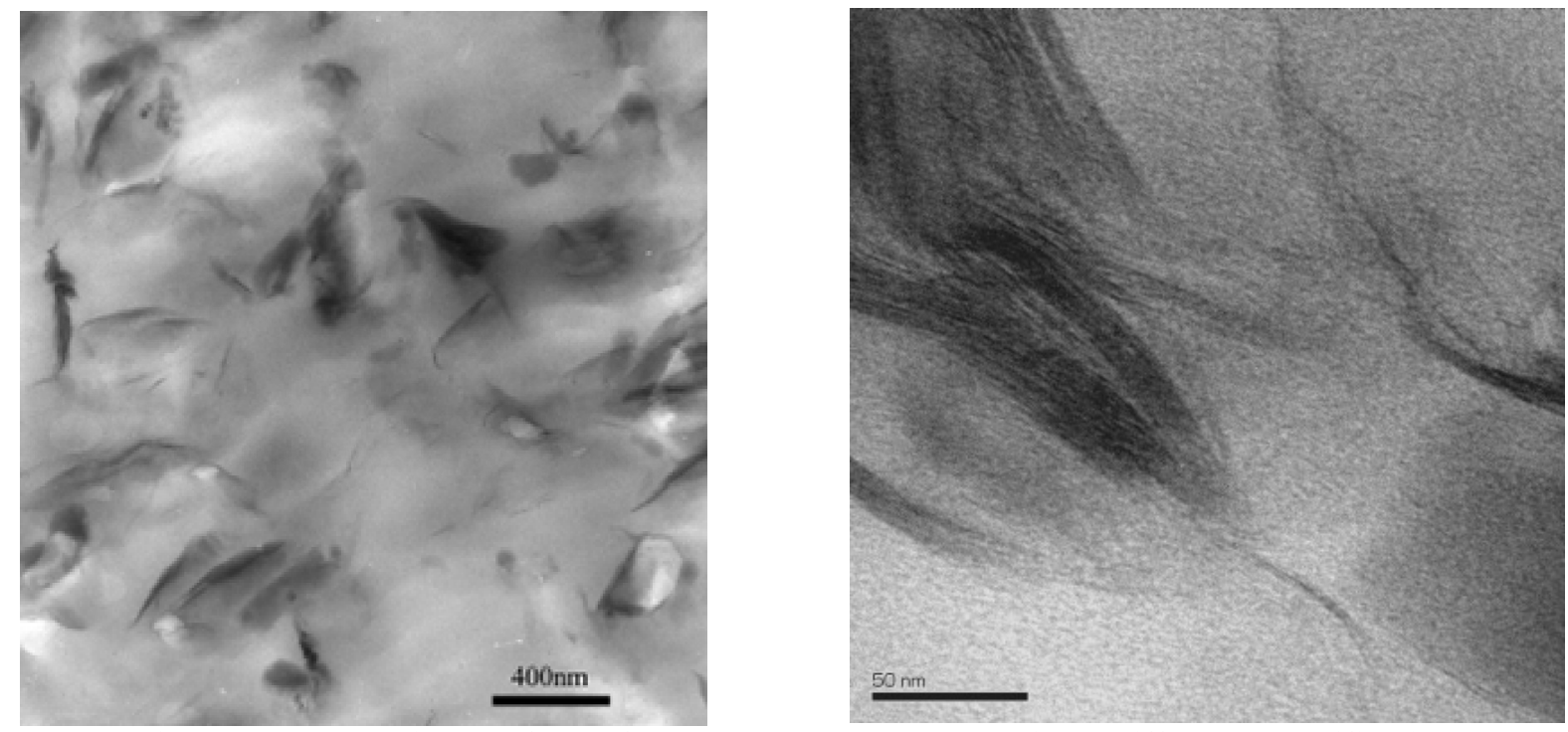

Figure 12 : TEM picture of PBT flame retarded nanocomposite at different magnifications

In the flame retarded PP matrix, the clay appears as agglomerated platelets. When we look more closely to the agglomerated particles, intercalation is observed into the platelets.
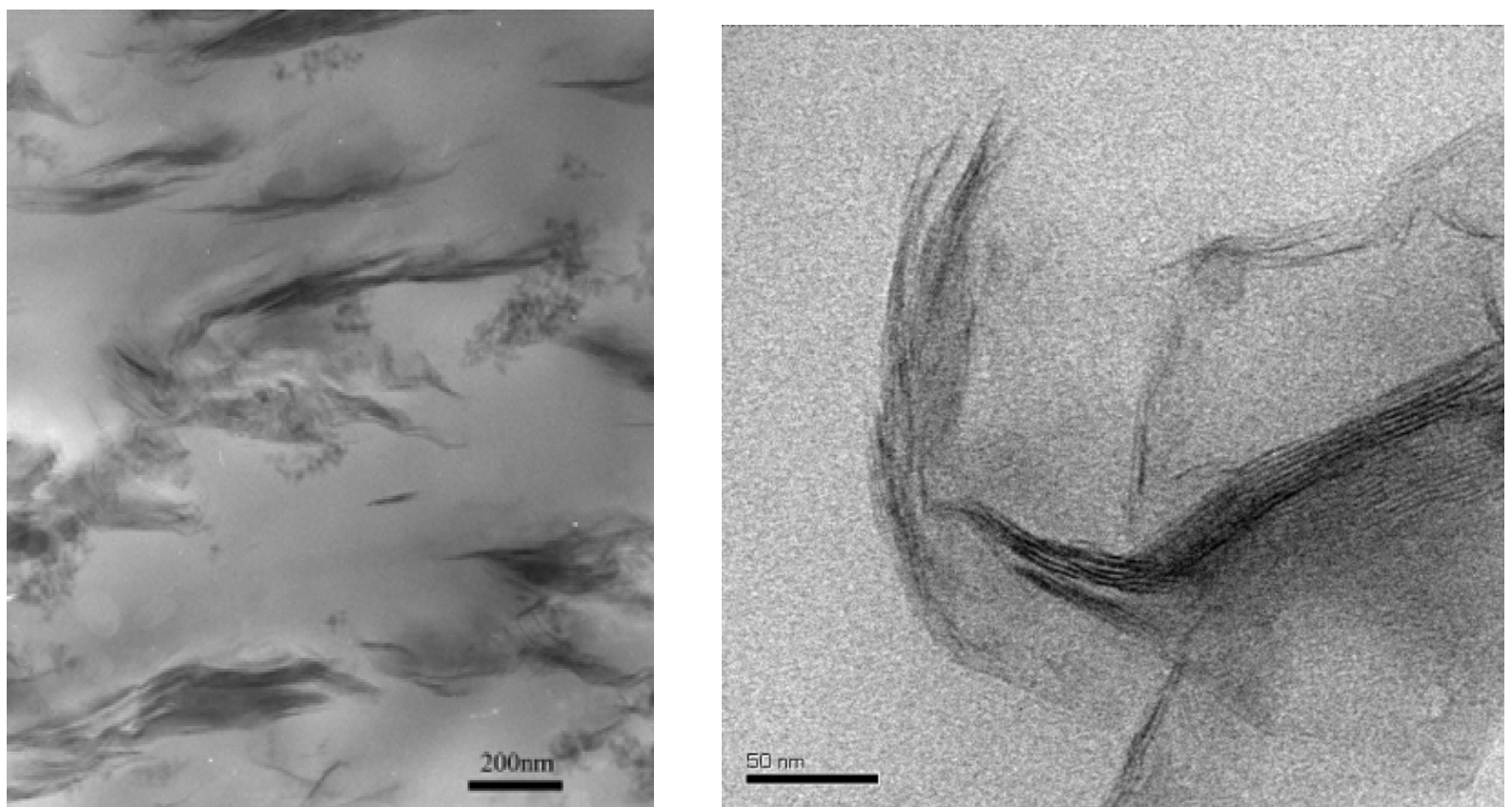

Figure 13 : TEM picture of PP flame retarded nanocomposite at different magnifications

\section{Discussion}

Table 5 summarizes the results of the different analyses for PLS and PFRLS nanocomposites. A comparison of the results obtained for the different PFRNC with the different techniques is very interesting. For PBT and PP they are consistent and tend to the same conclusion: a bad 
dispersion has been obtained for both composites. In the case of PA6 composite, an apparent contradiction is observed between the results. With XRD and TEM, it can be assumed that an exfoliated structure has been obtained, melt rheology indicates that a nanodispersion is achieved whereas NMR suggests a structure with tactoids and with potential intercalation. The representativeness of the TEM pictures has been ensured so that the dispersion of the clay in the flame retarded polyamide 6 is near the exfoliation what is confirmed by the XRD analyses. This might lead to the conclusion that the NMR methods would not be capable in the case of flame retarded nanocomposites using the assumptions we have done for neat nanocomposites.

Table 5 : summary of the results obtained with the different analytical methods

\begin{tabular}{|c|c|c|c|c|}
\hline & XRD & Melt rheology & Solid-state NMR & TEM \\
\hline $\begin{array}{c}\text { PA6 } \\
\text { nanocomposite }\end{array}$ & Absence of peak & $\begin{array}{c}\text { Nanodispersion } \\
\text { shear thinning } \eta=-0.42\end{array}$ & $\begin{array}{c}\text { Exfoliation } \\
\mathrm{f}=0.81 ; \mathrm{e}=98 \%\end{array}$ & Exfoliation \\
\hline $\begin{array}{c}\text { PA6 flame } \\
\text { retarded } \\
\text { nanocomposite }\end{array}$ & Absence of peak & $\begin{array}{c}\text { Pronounced shear } \\
\text { thinning } \eta=-0.56\end{array}$ & $\begin{array}{l}\text { Intercalation }+ \\
\text { tactoids } \\
\mathrm{f}=0.39 ; \mathrm{e}=50 \% \\
\end{array}$ & Exfoliation \\
\hline $\begin{array}{c}\text { PBT } \\
\text { nanocomposite }\end{array}$ & $\begin{array}{l}\text { Intercalation } \\
\text { Peak at } 2.2^{\circ} \\
\text { compared with } 4.7^{\circ} \\
\text { for neat C30B }\end{array}$ & $\begin{array}{l}\text { Pronounced shear } \\
\text { thinning } \eta=-0.67\end{array}$ & $\begin{array}{l}\text { Intercalation }+ \\
\quad \text { tactoids } \\
\mathrm{f}=0.5 ; \mathrm{e}=67 \%\end{array}$ & $\begin{array}{l}\text { Intercalation, } \\
\text { Tactoids of } 8 / 10 \\
\text { platelets }\end{array}$ \\
\hline $\begin{array}{c}\text { PBT flame } \\
\text { retarded } \\
\text { nanocomposite }\end{array}$ & $\begin{array}{l}\text { Microcomposite } \\
\text { Peak at } 4.6^{\circ} \\
\text { compared with } 4.7^{\circ} \\
\text { for neat C30B }\end{array}$ & $\begin{array}{l}\text { Pronounced shear } \\
\text { thinning } \eta=-0.65\end{array}$ & $\begin{array}{c}\text { Slight intercalation } \\
\text { big tactoids } \\
\mathrm{f}=0.11 ; \mathrm{e}=29 \%\end{array}$ & $\begin{array}{l}\text { Big agglomerates, } \\
\text { slight intercalation }\end{array}$ \\
\hline PP nanocomposite & $\begin{array}{l}\text { Microcomposite } \\
\text { Peak at } 3.4^{\circ} \\
\text { compared with } 3.6^{\circ} \\
\text { for neat C20A }\end{array}$ & $\begin{array}{c}\text { Microcomposite } \\
\text { No cross over and small } \\
\text { shear thinning }\end{array}$ & $\begin{array}{c}\text { Slight intercalation } \\
\text { big tactoids } \\
\mathrm{f}=0.10 ; \mathrm{e}=44 \%\end{array}$ & $\begin{array}{c}\text { Exfoliated } \\
\text { platelets, big } \\
\text { tactoids and slight } \\
\text { intercalation }\end{array}$ \\
\hline $\begin{array}{l}\text { PP flame retarded } \\
\text { nanocomposite }\end{array}$ & $\begin{array}{c}\text { Intercalation } \\
\text { Peak at } 2.65^{\circ} \\
\text { compared with } 3.6^{\circ} \\
\text { for neat C20A }\end{array}$ & $\begin{array}{c}\text { Microcomposite } \\
\text { Small shear thinning }\end{array}$ & $\begin{array}{l}\text { Intercalation but } \\
\text { tactoids } \\
\mathrm{f}=0.08 ; \mathrm{e}=58 \%\end{array}$ & $\begin{array}{l}\text { Big agglomerates } \\
\text { But intercalation }\end{array}$ \\
\hline
\end{tabular}

In the particular case of the NMR measurements, the calculated parameters are underestimated. This underestimation can be attributed to an effect of the flame retardant in the formulation since the NMR method has already been successfully used to quantify the dispersion in PA6-cloisite 30B nanocomposite. The observation of the proximity of the flame retardant agglomerated particles using TEM combined with EDS analyses (Figure 14) reveals that at the interface polymer flame retardant (FR) a part of the clay particles are located around the FR so that one part of the delaminated platelet is in contact with the polymer the other is near the FR. It means that only platelets far enough of the FR will contribute to the efficiency of the spin diffusion. As the total amount of clay is used in the calculation, the T resulting calculated values will be underestimated. 


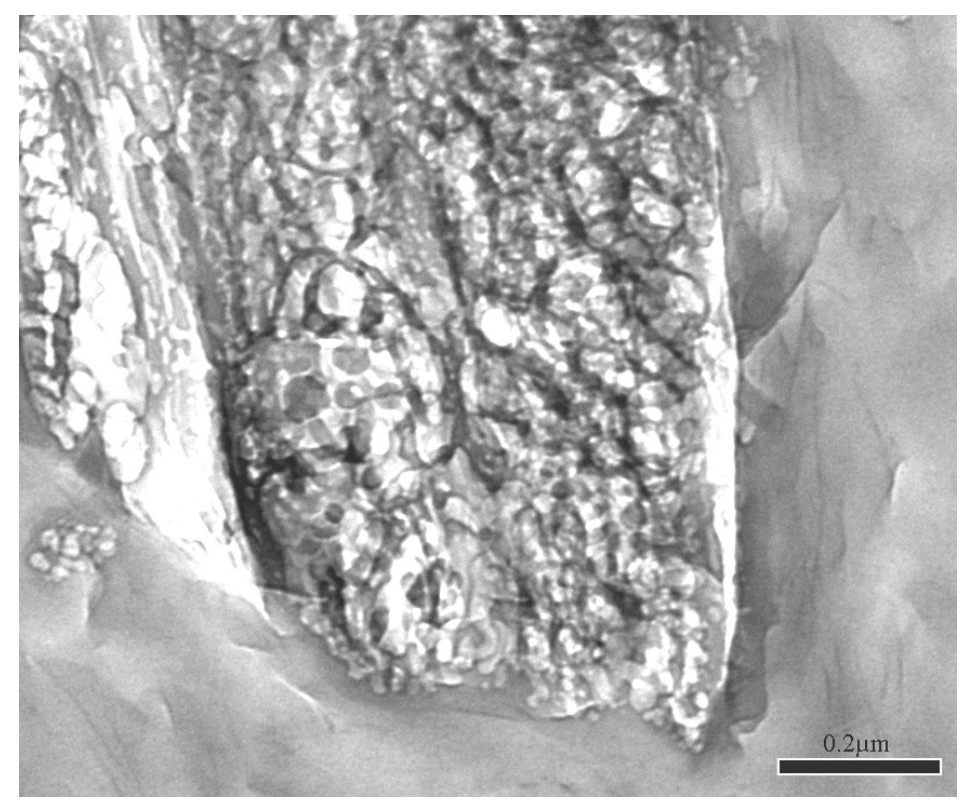

Figure 14 : TEM picture of a flame retardant particle surrounded by Cloisite platelets

A comparison of the dispersion achieved in PLS and PFRLS nanocomposites enables to evaluate the influence of the presence of flame retardant on the dispersion of the clay. No global trend is observed. Three different conclusions can be made according to the polymer and the type of FR used. In the case of PA6 composites, the presence of FR has no influence on the dispersion except the fact that some amount of the platelets are located around the FR. In the case of PBT, the flame retardant decreases the degree of dispersion and for PP the dispersion state is increased by addition of FR. Further investigations on the relative position of the FR particles and the clay platelets in the PFRLS nanocomposites could probably give some clues on the reasons of the different observations.

\section{Conclusion}

The methods classically used for the characterisation of polymer nanocomposite have been applied to polymer flame retarded nanocomposite. SEM, XRD, melt rheology and solid state NMR analyses have been performed on PA6, PP and PBT nanocomposite flame retarded with a phosphorous compound. SEM permits to show the dispersion of the flame retardant in the polymers and to confirm that the dispersion of the clay is submicronic. Analyses of the morphology of flame retarded composites by TEM, XRD, melt rheology and NMR show some differences especially observed when platelets are nanodispersed. For PBT and PP flame retarded nanocomposites all the techniques give the same conclusion, i.e. a poor dispersion s. For PA6, XRD and TEM show the exfoliation of the platelets, melt rheology indicates nanodispersion and NMR suggests intercalation and some tactoids. As the 
representativity of the TEM images have been carefully checked, NMR approach leads to apparent discrepancy in the presence of flame retardant. Further investigations suggest that some amount of individual platelets are located around flame retardant tactoids leading to underestimate the nanodispersion state. The influence of the flame retardant on the dispersion of the nanoparticles has been investigating. No global trend has been observed. In PP, the flame retardant seems to enable to obtain a better dispersion unlike in PBT the opposite observation is made. For PA6, no influence of the presence of the phosphorous flame retardant is detected except the fact that a significant amount of platelets are located around the FR.

\footnotetext{
${ }^{1}$ S. Bourbigot, M. Le Bras, F. Dabrowski, J.W. Gilman, T. Kashiwagi, Fire Mater 24 (2000) 201-208

${ }^{2}$ F. Dabrowski, M.Le Bras, L. Cartier, S. Bourbigot, Journal of Fire Sciences 19 (3) (2001) 219-241

${ }^{3}$ G. Beyer, Fire Mater. 25 (2001) 193-197

${ }^{4}$ F. Samyn, S. Bourbigot, C. Jama, S. Nazare, B. Biswas, R. Hull, A. Fina, A. Castrovinci, G. Camino, M. Hagen, M. Delichatsios, in preparation

${ }^{5}$ Wagener R and Reisinger TJG. Polymer 44 (2003) 7513-7518.

${ }^{6}$ S. Bourbigot; D.L. VanderHart, J.W. Gilman, W.H. Awad, R.D. Davis, A.B. Morgan, C.A. Wilkie, J. Polym. Sci. B, Polym. Phys., 41 (24), pp. 3188-3213
} 